\title{
APLICAÇÃO DE REDES NEURAIS ARTIFICIAIS PARA ESTIMAÇÃO DA ALTURA DE POVOAMENTOS EQUIÂNEOS DE EUCALIPTO ${ }^{1}$
}

\begin{abstract}
Mayra Luiza Marques da Silva Binoti² ${ }^{2}$ Daniel Henrique Breda Binoti ${ }^{3}$ e Helio Garcia Leite ${ }^{4}$
RESUMO - Este trabalho teve como objetivos aumentar a precisão das estimativas de altura de árvores e diminuir a necessidade de aferição da altura em campo, levando à redução dos custos no inventário florestal através da construção e validação de um modelo de estimação da altura de árvores em povoamentos de eucalipto com a utilização de redes neurais artificiais. Os dados utilizados consistiram em três clones, compreendendo cerca de 3.000 árvores em 145 parcelas permanentes com área média de 215 m², mensuradas em seis ocasiões (idades). As variáveis utilizadas para estimar a altura total das árvores dividiram-se em quantitativas: idade (meses), diâmetro com casca a 1,30 m de altura a partir da superfície do solo (dap) e altura dominante média da parcela; e qualitativa: tipo de solo com as respectivas classes. Para validação e aplicação da metodologia proposta, foram consideradas duas situações: (a) quando há a introdução de um novo material genético e não existem informações sobre a relação hipsométrica deste; (b) quando já se conhece a tendência de crescimento em altura dos povoamentos implantados, obtida pela existência de medições em parcelas de IFC. Com as metodologias testadas, obtiveram-se valores de coeficiente de correlação superiores a 0,99. As metodologias mostraram-se eficientes para alcançar os objetivos propostos, garantindo alta precisão das estimativas obtidas através das redes neurais artificiais.
\end{abstract}

Palavras-chave: Inventário florestal; Relação hipsométrica; Eucalipto.

\section{APPLICATION OF ARTIFICIAL NEURAL NETWORKS TO ESTIMATE THE HEIGHT OF EVEN-AGED STANDS OF EUCALYPTUS}

\begin{abstract}
The objective of this study was to increase the accuracy of estimates of tree height and to reduce the need for measurement in field of height, leading to reduction of costs on forest inventory through the construction and validation of a model for estimating the height of trees in stands of eucalyptus using artificial neural networks. The data used in the experiment consisted of three clones, comprising nearly 3,000 trees on 145 permanent plots with an average area of $215 \mathrm{~m}^{2}$, measured on six occasions (ages). The variables used to estimate the total tree height were divided into quantitative and qualitative. The quantitative variables were: age (months), shell diameter at $1.30 \mathrm{~m}$ height from the ground surface (dbh) and average dominant height in the plot. The qualitative variables was the soil type in their respective classes. For validation and application of the proposed methodology two situations were considered: (a) when there is the introduction of new genetic material and there is no information about the hypsometric relation thereof, and (b) when the trend of growth in height of the stands implanted obtained by the existence of measurements on inventory plots is already known. Values of correlation coefficient higher than 0.99 were achieved with the tested methodologies. The methods were effective to achieve the proposed objectives, ensuring high precision of the estimates obtained through artificial neural networks.
\end{abstract}

Keywords: Artificial neural networks; Forest inventory; Hipsometric relationship.

\footnotetext{
${ }^{1}$ Recebido em 18.07.2011 aceito para publicação em 02.07.2013.

${ }^{2}$ Departamento de Engenharia Florestal da Universidade Federal dos Vales do Jequitinhonha e Mucuri, Brasil. E-mail: $<$ mayrabinoti@gmail.com>.

${ }^{3}$ Programa de Pós-Graduação em Ciência Florestal da Universidade Federal de Viçosa, UFV, Brasil. E-mail: $<$ danielhbbinoti@gmail.com>.

${ }^{4}$ Departamento de Engenharia Florestal da Universidade Federal de Viçosa, UFV, Brasil. E-mail: <hgleite@gmail.com>.
} 


\section{INTRODUÇÃO}

A estimação de estoques de crescimento e de colheita é importante elemento no manejo florestal, uma vez que fornece informações quantitativas sobre a floresta, auxiliando na definição de planos de manejo e em análises econômicas de prescrições de manejo.

A quantificação do estoque volumétrico é realizada por meio de inventários florestal contínuo (IFC) ou temporário. Ambos consistem basicamente na medição de amostras representativas da população, constituída pelas unidades de amostra (parcelas). O volume de madeira em cada uma dessas parcelas é obtido pela aplicação de modelos volumétricos, de razão volumétrica ou de afilamento, que em sua maioria possuem como variáveis independentes o diâmetro com casca a 1,3 m de altura a partir da superfície do solo (dap) e a altura total da árvore.

Estudos sobre modelos, procedimentos e equipamentos para a mensuração da altura de árvores são extremamente importantes, visto que a medição da altura das árvores é considerada componente significativo no custo do inventário florestal (LEITE; ANDRADE, 2004). A redução dos custos da medição das árvores pode ser obtida pelo uso da relação hipsométrica, como proposto por Ker e Smith em 1957, em que a partir da medição das alturas e diâmetros (dap) de algumas árvores se pode estimar a altura das demais árvores da parcela. Contudo, a relação hipsométrica é afetada por fatores ambientais e características do povoamento, como: capacidade produtiva, idade, material genético, variações ambientais e características qualitativas (CURTIS, 1967; ZHANG et al., 1997; FANG; BAILEY, 1998).

A inclusão de características do povoamento nos modelos hipsométricos, como índice de local e idade, resulta em vantagens, como a obtenção de estimativas mais precisas e o maior realismo biológico, tornando a equação aplicável em diferentes locais. As principais dificuldades para a inclusão de muitas variáveis em um modelo hipsométrico são a dificuldade de modelagem e quantificação das influências sobre a variável a ser estimada (altura total). Essas relações apresentam características não lineares ou valores categóricos, a exemplo do tipo de solo, podendo ser incluídas em regressões somente como variáveis binárias e ocasionar aumento na complexidade de modelagem.
A obtenção das medições de altura é outra grande dificuldade do inventário florestal, devido ao fato de a sua aferição ser realizada indiretamente. Problemas como falta de visibilidade do topo da árvore em floresta densa e a ocorrência de ventos pode tornar a medição impraticável em alguns casos, principalmente em plantios de eucalipto.

Uma abordagem alternativa para a modelagem da relação hipsométrica consiste no uso de redes neurais artificiais (RNA). Essas redes são sistemas computacionais paralelos constituídos por unidades de processamento simples, também denominadas neurônios artificiais ou nodos, conectadas entre si de maneira específica para desempenhar determinada tarefa (BINOTI, 2010; BINOTI et al., 2012a). Os neurônios artificiais são modelos matemáticos simplificados dos neurônios biológicos e processam as informações recebidas e ponderadas por pesos sinápticos, fornecendo uma única resposta (HAYKIN, 2001; BRAGA et al., 2007).

Em alguns casos, as RNA têm apresentado desempenho superior aos modelos de regressão devido a diversos fatores, como: estrutura maciça e paralelamente distribuída (camadas); habilidade de aprender e generalizar, que as tornam capazes de resolver problemas complexos; são tolerantes a falhas e ruídos; podem modelar diversas variáveis e suas relações não lineares; possibilidade de modelagem com variáveis categóricas (qualitativas), além das numéricas (quantitativas); e analogia neurobiológica (HAYKIN, 2001).

A utilização de redes neurais artificiais (RNA) tem-se mostrado alternativa promissora em relação às técnicas de regressão no manejo dos recursos florestais. Diversos trabalhos têm sido desenvolvidos visando à sua adaptação e parametrização para diversas situações, como a estimação do volume de árvores (SILVA et al., 2009), crescimento e produção (BINOTI, 2010), taper (DIAMANTOPOULOU, 2005; LEITE et al., 2010), modelos hipsométricos (BINOTI et al., 2012a) e modelagem da distribuição diamétrica (BINOTI et al., 2012b), entre outras aplicações.

A modelagem da altura de povoamentos florestais se enquadra na tarefa de aprendizagem de RNA denominada aproximação de funções (BINOTI, 2010). Essa tarefa consiste em treinar uma rede neural que aproxime a função desconhecida $f(x)$, que descreve o mapeamento dos pares de entrada-saída $\left\{\left(x_{1}, y_{1}\right)\right.$, 
$\left.\left(x_{2}, y_{2}\right), \ldots,\left(x_{n}, y_{n}\right)\right\}$ de um conjunto de $n$ exemplos de treinamento (HAYKIN, 2001). O treinamento, também denominado aprendizagem, consiste no ajuste dos parâmetros da rede a partir de dados de treinamento (exemplos), a fim de desempenhar determinada tarefa (HAYKIN, 2001; BRAGA et al., 2007).

Visando aumentar a precisão das estimativas de altura, reduzir os custos no inventário florestal e diminuir a necessidade de aferição da altura em campo, este trabalho teve como objetivos propor, construir e validar um modelo de estimação da altura de árvores em povoamentos de eucalipto com a utilização de redes neurais artificiais.

\section{MATERIAL E MÉTODOS}

\section{Dados}

Os dados utilizados neste estudo foram provenientes de medições de parcelas permanentes de inventários florestais contínuos (IFC) realizados em povoamentos de clones de eucalipto localizados em áreas com cinco tipos de solo e três clones, denominados C1, C2 e C3. Os dados utilizados são de 3.000 árvores distribuídas em 145 parcelas permanentes com área de cerca de $220 \mathrm{~m}^{2}$, mensuradas em seis ocasiões (idades).

As variáveis utilizadas para estimar a altura total das árvores foram classificadas em quantitativas: idade (meses), diâmetro com casca a 1,30 m de altura do solo (dap) e altura dominante média da parcela; e qualitativas: tipo de solo com as respectivas classes.

\section{Cenários}

Para validação e aplicação da metodologia proposta, foram consideradas duas situações:

(a) Quando há a introdução de um novo material genético e não existem informações sobre a relação hipsométrica deste.

(b) Quando já se conhece a tendência de crescimento em altura dos povoamentos implantados, obtida pela existência de medições em parcelas de IFC.

Para o cenário (a), utilizou-se a primeira medição do clone C1. As informações deste clone foram estratificadas em três classes em função da amplitude da altura dominante. O treinamento das redes foi feito com dados de uma parcela selecionada aleatoriamente em cada tipo de solo e classe de altura dominante, totalizando 15 parcelas (cinco tipos de solo x três classes de $H d$ ). Nessas parcelas foram medidos os dap e a altura de todas as árvores.

Na simulação do cenário (b), utilizaram-se duas abordagens: (1) considerando uma rede para cada clone e (2) empregando uma rede genérica para todo o povoamento, tendo a inclusão do clone como variável categórica. Os dados foram estratificados em três classes em função da dispersão da altura dominante, com o intuito de abranger todas as classes de capacidade produtiva. Em ambas as abordagens, selecionaram-se $80 \%$ dos dados para o treinamento das redes, tendo o cuidado de selecionar parcelas em todas as combinações de variáveis quantitativas (clone x tipo de solo). Os demais dados (20\%) foram utilizados no processo de generalização, ou seja, na aplicação em um conjunto de dados novos para a RNA.

\section{Treinamento e avaliação das RNA}

A estimativa da altura foi simulada com todas as combinações possíveis das variáveis de entrada, totalizando seis combinações. As redes treinadas foram do tipo perceptrons de múltiplas camadas, comumente conhecidas como MLP (Multilayer Perceptron), que consistem em duas camadas de neurônios artificiais que processam os dados (camada intermediária e camada de saída) e uma camada de neurônios artificiais que apenas recebem os dados (camada de entrada) e direciona-os à camada intermediária. Para obtenção das redes neurais artificiais, utilizou-se o software Statistica 7 (STATSOFT, INC, 2007).

As melhores RNA foram selecionadas com base na correlação entre a altura observada e a altura estimada pelas redes $\left(r_{H \mathbb{H}}\right)$ e na estabilidade dos índices de treinamento das redes, fornecidos pelo software nas fases de treinamento, seleção e avaliação. As redes selecionadas foram aplicadas aos dados das demais parcelas permanentes para estimar a altura total das árvores individuais.

As estimativas das alturas totais através das RNA foram avaliadas com base nos seguintes critérios: dispersão dos erros percentuais, histograma de frequência dos erros percentuais e a raiz quadrada do erro médio (RMSE Root Mean Square Error). O erro percentual obtido foi dado por:

Revista Árvore, Viçosa-MG, v.37, n.4, p.639-645, 2013 


$$
\text { erro }_{\%}=\frac{(\widehat{H}-H)}{H} \times 100
$$

em que $H$ é a altura total observada nos inventários, e $\widehat{H}$ é a altura total estimada pela RNA.

A raiz quadrada do erro médio avalia a diferença quadrática média entre os valores observados e estimados. Quanto menor o RMSE, melhor a precisão da estimativa, sendo a situação ótima quando é igual a zero (MEHTÄTALO et al., 2006):

$$
\operatorname{RMSE}(\%)=\frac{100}{\bar{H}} \sqrt{\frac{\sum_{i=1}^{n}\left(H_{i}-\widehat{H}_{i}\right)^{2}}{n}}
$$

em que $\bar{H}$ é a média das alturas totais observadas e n, o número total de observações.

\section{RESULTADOS}

\section{Cenário (a)}

Para o cenário (a), simulou-se a introdução de material genético ao qual não se conhece a sua relação hipsométrica. A estratificação em função da altura dominante em três classes resultou em classes com amplitude de $5 \mathrm{~m}$ e centro de classes com valores de 10, 15 e 20 m. Todas as possíveis combinações de variáveis de entrada foram testadas, sendo as combinações que melhor expressaram a relação hipsométrica: $H=\mathrm{f}(H d$, dap $), H=\mathrm{f}(H d$, dap,$I), H=\mathrm{f}(H d$, dap, $I$, solo $)$ e $H=$ $\mathrm{f}(\mathrm{Hd}$, dap, solo $)$. As características das redes selecionadas com base no índice de treinamento e na correlação entre as variáveis são apresentadas na Tabela 1 .

As redes selecionadas foram aplicadas aos dados das demais parcelas permanentes para estimar a altura total das árvores com base no tipo de solo, dap, altura dominante média e idade. E a dispersão e frequência relativa dos erros percentuais mostraram alta precisão das estimativas (Figura 1).

\section{Cenário (b)}

A simulação do cenário (b) foi feita com dados que possuíam seis medições em idades variando de 25 a 84 meses. Todas as possíveis combinações de variáveis de entrada foram testadas, sendo as combinações, considerando a abordagem individual por clone e para todo o povoamento, que melhor expressaram a relação hipsométrica apresentadas na Tabela 2. Selecionaram-se 15 redes com base nos índices de treinamento e na correlação entre as variáveis apresentadas na Tabela 2. Nas redes selecionadas, realizou-se a generalização para comprovar a aplicação da metodologia, sendo os gráficos de resíduos apresentados na Figura 2 e os histogramas percentuais de resíduos, na Figura 3.

\section{DISCUSSÃO}

Para aplicação da metodologia e considerando o cenário (a), obtiveram-se resultados satisfatórios para a estimação de alturas de clones introduzidos pela empresa. As redes 1 e 2 não apresentaram tendenciosidade na dispersão dos resíduos, enquanto as redes 2 e 3 apresentaram pequena tendência de subestimação e de superestimação dos valores estimados, respectivamente (Figura 1). Contudo, as relações funcionais demonstraram-se satisfatórias para a estimação da altura, para o cenário em questão.

Para a aplicação da metodologia considerando o cenário (b), obtiveram-se resultados satisfatórios para a construção de redes estratificando para cada clone e a construção de uma rede genérica, considerando todos

Tabela 1 - Características das redes neurais artificiais (RNA) selecionadas para estimar a altura total das árvores na situação (a).

Table 1 - Characteristics of artificial neural networks (ANN) selected to estimate the total height of trees in the

\begin{tabular}{|c|c|c|c|c|c|c|}
\hline RNA & $r_{H \hat{H}}$ & Índice do treino** & Índice da seleção** & Índice da avaliação** & Arquitetura* & Variáveis de entrada \\
\hline 1 & 0,9986 & 0,044 & 0,068 & 0,056 & $2-5-1$ & Hd, dap \\
\hline 2 & 0,9987 & 0,043 & 0,065 & 0,054 & $3-2-1$ & Hd, dap, I \\
\hline 3 & 0,9980 & 0,059 & 0,069 & 0,066 & $7-3-1$ & Hd, dap, s \\
\hline 4 & 0,9986 & 0,044 & 0,069 & 0,055 & $8-6-1$ & Hd, dap, I, S \\
\hline
\end{tabular}
situation (a).

* Número de neurônios em cada camada. ** Índices do treino (obtenção da rede), seleção (parada do treino) e avaliação (qualidade da rede treinada) que devem ser estáveis, ou seja, pouca variação entre eles. Hd = altura dominante $(\mathrm{m})$, dap = diâmetro com casca a $1,30 \mathrm{~m}$ de altura $(\mathrm{cm}), \mathrm{I}=$ idade (meses), $\mathrm{S}=$ solo e $r_{H \hat{H}}=$ correlação entre alturas total estimada e observada.

Revista Árvore, Viçosa-MG, v.37, n.4, p.639-645, 2013 

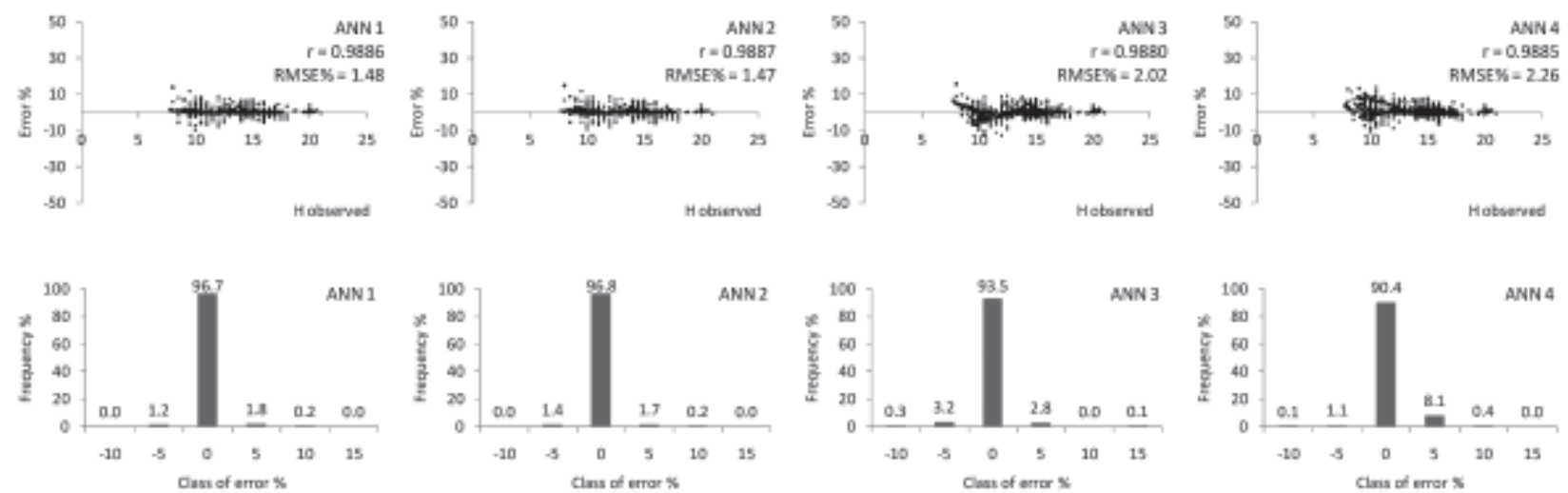

Figura 1 - Dispersão e histograma de frequência dos erros percentuais da generalização das RNA para estimar a altura total das árvores na situação (a). Os números em cada barra indicam os percentuais de casos por classe de erro \%.

Figure 1 -Dispersion and frequency histogram of percentage errors of the generalization of ANN to estimate the total height of trees in the situation (a). The numbers in each bar indicate the percentage of cases for error class\%.

Tabela 2 - Características das redes neurais artificiais (RNA) selecionadas para estimar a altura total das árvores na situação (b). Table 2 - Characteristics of artificial neural networks (ANN) selected to estimate the total height of trees in situation (b).

\begin{tabular}{|c|c|c|c|c|c|c|c|c|c|}
\hline \multirow[b]{2}{*}{ RNA } & \multirow[b]{2}{*}{ Clone } & \multirow[b]{2}{*}{ Arquitetura } & \multirow[b]{2}{*}{$\begin{array}{l}\text { Variáveis } \\
\text { de entrada }\end{array}$} & \multirow[b]{2}{*}{$r_{H}$} & \multicolumn{3}{|c|}{ Treinamento } & \multicolumn{2}{|c|}{ Generalização } \\
\hline & & & & & $\begin{array}{c}\text { Índice do } \\
\text { treino }\end{array}$ & $\begin{array}{c}\text { Índice da } \\
\text { seleção }\end{array}$ & $\begin{array}{l}\text { Índice da } \\
\text { avaliação }\end{array}$ & $r_{H H}$ & RMSE\% \\
\hline 1 & $\mathrm{C}_{1}$ & $2-5-1$ & Hd, dap & 0,9939 & 0,11 & 0,11 & 0,11 & 0,9924 & 3,14 \\
\hline 2 & $\mathrm{C}_{1}$ & $6-5-1$ & Hd, dap, S & 0,9943 & 0,11 & 0,11 & 0,11 & 0,9926 & 3,06 \\
\hline 3 & $\mathrm{C}_{1}$ & $7-8-1$ & Hd, dap, I, S & 0,9958 & 0,09 & 0,09 & 0,09 & 0,9948 & 2,55 \\
\hline 4 & $\mathrm{C}_{1}$ & $3-6-1$ & Hd, dap, I & 0,9961 & 0,09 & 0,09 & 0,09 & 0,9953 & 2,43 \\
\hline 5 & $\mathrm{C}_{2}$ & $10-3-1$ & Hd, dap, S & 0,9846 & 0,178 & 0,178 & 0,164 & 0,9816 & 4,90 \\
\hline 6 & $\mathrm{C}_{2}^{2}$ & $2-3-1$ & Hd, dap & 0,9902 & 0,155 & 0,126 & 0,120 & 0,9860 & 4,42 \\
\hline 7 & $\mathrm{C}_{2}^{2}$ & $11-3-1$ & Hd, dap, I, S & 0,9922 & 0,132 & 0,119 & 0,113 & 0,9921 & 3,20 \\
\hline 8 & $\mathrm{C}_{2}^{2}$ & $3-5-1$ & Hd, dap, I & 0,9919 & 0,142 & 0,115 & 0,105 & 0,9935 & 2,82 \\
\hline 9 & $\mathrm{C}_{3}^{2}$ & $2-4-1$ & Hd, dap & 0,9853 & 0,169 & 0,172 & 0,174 & 0,9856 & 5,00 \\
\hline 10 & $\mathrm{C}_{3}^{3}$ & $8-2-1$ & Hd, dap, S & 0,9870 & 0,157 & 0,164 & 0,164 & 0,9846 & 4,84 \\
\hline 11 & $\mathrm{C}_{1}, \mathrm{C}_{2}, \mathrm{C}_{3}$ & $15-1-1$ & Hd, dap, C, S & 0,9855 & 0,170 & 0,171 & 0,168 & 0,9833 & 4,8 \\
\hline 12 & $C_{1}, C_{2}, C_{3}^{3}$ & $6-5-1$ & Hd, dap, I, C & 0,9902 & 0,142 & 0,137 & 0,137 & 0,9897 & 3,7 \\
\hline 13 & $C_{1}, C_{2}, C_{3}^{3}$ & $2-2-1$ & Hd, dap & 0,9916 & 0,131 & 0,126 & 0,129 & 0,9895 & 3,8 \\
\hline 14 & $C_{1}, C_{2}, C_{3}^{3}$ & $12-4-1$ & Hd, dap, S & 0,9921 & 0,127 & 0,122 & 0,125 & 0,9899 & 3,7 \\
\hline 15 & $\mathrm{C}_{1}, \mathrm{C}_{2}, \mathrm{C}_{3}$ & $13-4-1$ & Hd, dap, I, S & 0,9943 & 0,110 & 0,104 & 0,105 & 0,9934 & 3,0 \\
\hline
\end{tabular}

${ }^{*}$ Número de neurônios em cada camada. ** Índices do treino (obtenção da rede), seleção (parada do treino) e avaliação (qualidade da rede treinada) que devem ser estáveis, ou seja, pouca variação entre eles. Hd = altura dominante $(\mathrm{m})$, dap = diâmetro com casca a $1,30 \mathrm{~m}$ de altura (cm), I = idade (meses), S = solo, C = clone e $r_{H \hat{H}}=$ correlação entre altura total estimada e observada.

os clones. Pelo fato de se utilizarem medições em todas as idades do povoamento, todas as redes e em todas as relações funcionais utilizadas não apresentaram tendenciosidade e alta precisão, que são comprovadas pela pequena dispersão de resíduos apresentada nas Figuras 2 e 3. Contudo, recomenda-se a utilização de apenas uma rede para todo o povoamento, a fim de facilitar o processo de modelagem. Para as redes em questão, dispunha-se somente de informações de solo e clone, podendo a introdução de informações adicionais como precipitação e radiação, entre outras, aumentar a precisão das estimativas.

A aplicação da metodologia (a) e (b) em conjunto permite reduzir o tempo para a realização de um inventário

Revista Árvore, Viçosa-MG, v.37, n.4, p.639-645, 2013 
florestal. Com a obtenção das redes realizadas pelo emprego da metodologia (b), a realização do próximo inventário é somente com a mensuração do dap e das alturas das árvores dominantes do povoamento, que são necessárias também para a classificação da capacidade produtiva. Recomenda-se a mensuração da altura em somente algumas parcelas para o acompanhamento das estimativas geradas pelas redes e possíveis calibrações destas.

A aplicação da metodologia (a) reduz significativamente medições em clones recémintroduzidos no povoamento, pois se mede apenas
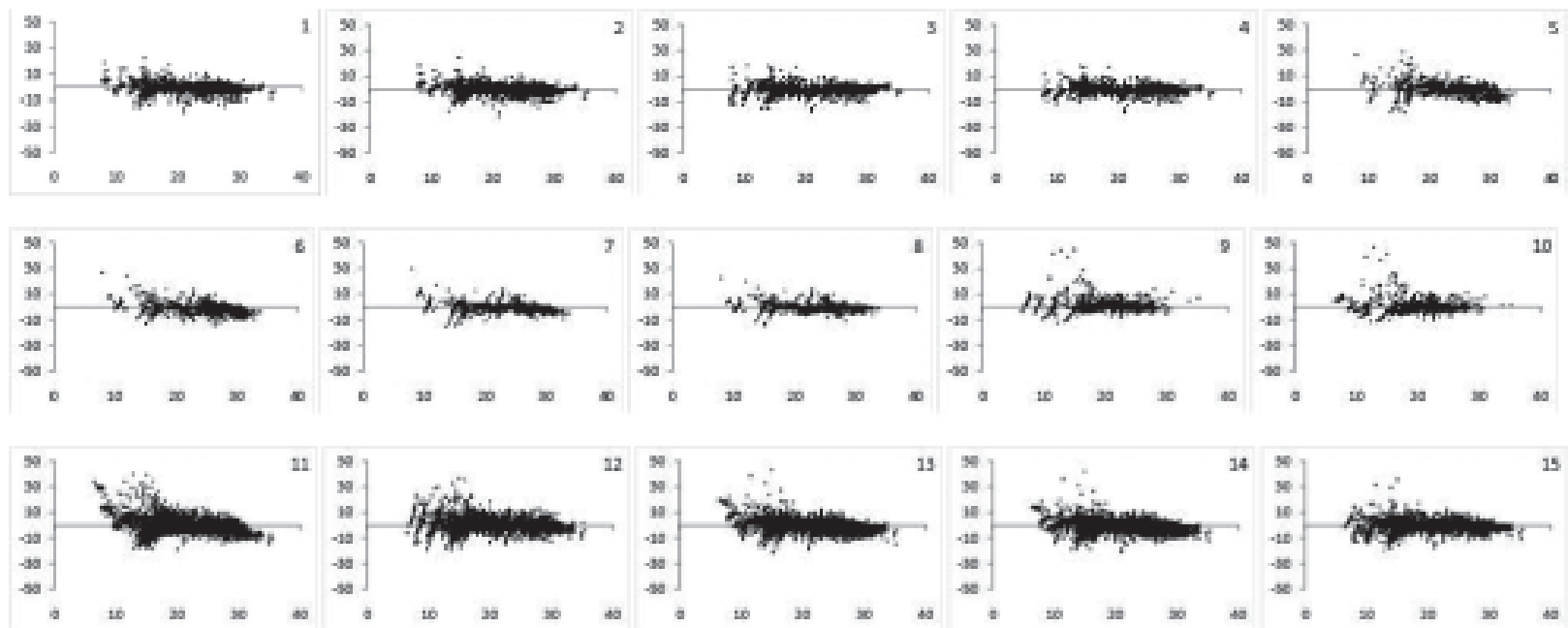

Figura 2 - Dispersão dos erros percentuais das estimativas da altura total pelas redes neurais artificiais (y), em função dos valores observados da altura total (x).

Figure 2 - Dispersion of the errors of estimates of the total height by artificial neural networks ( $y$ ) as a function of the observed values of total height $(x)$.
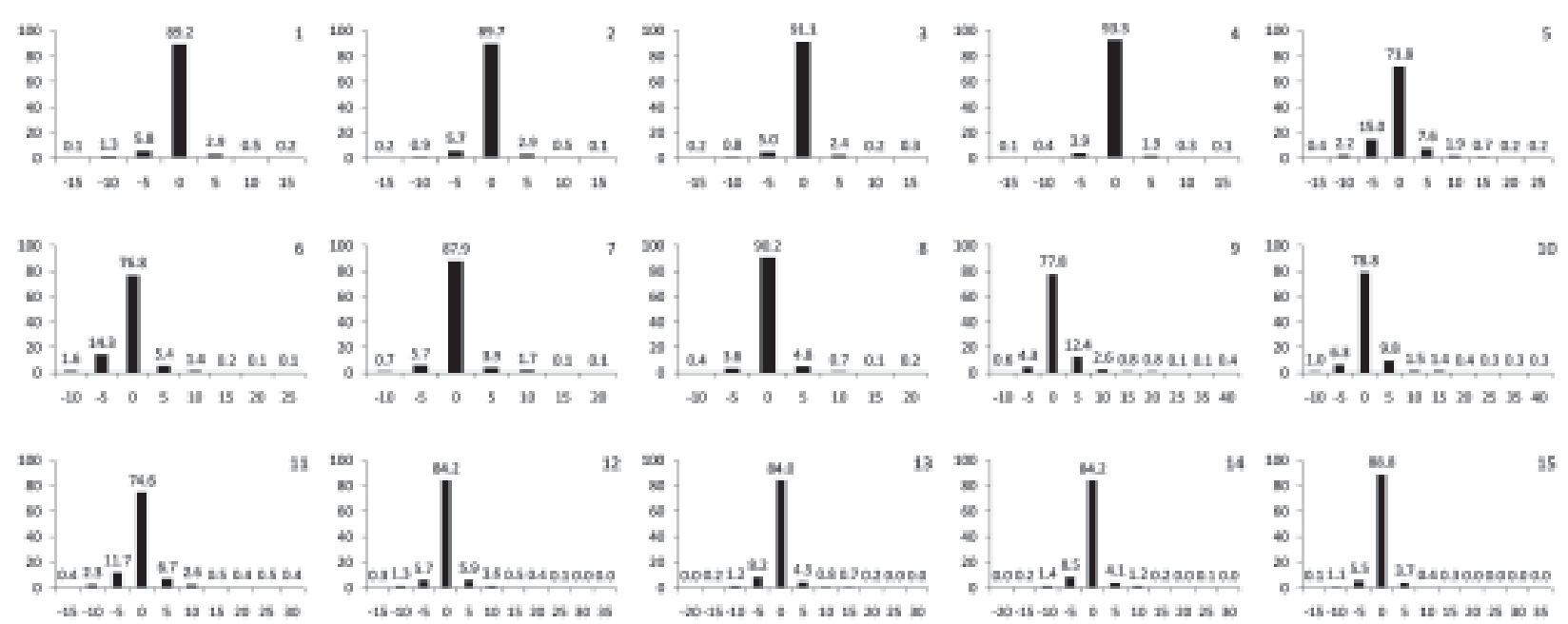

Figura 3 - Frequência percentual dos erros percentuais das estimativas da altura total pelas redes neurais artificiais (y) em função das classes de erros percentuais (x). Os números em cada barra indicam os percentuais de casos por classe de erro (\%).

Figure 3 - Frequency percentage of errors of estimates of the total height by artificial neural networks (y) according to the class of error percentage $(x)$. The numbers in each bar indicate the percentage of cases for error class (\%).

Revista Árvore, Viçosa-MG, v.37, n.4, p.639-645, 2013 
um número mínimo de parcelas por estrato de capacidade produtiva. A partir da obtenção da tendência de crescimento do novo clone, pode-se realizar a mensuração apenas do dap e das alturas dominantes, sendo as demais alturas estimadas como para a aplicação da metodologia (b), e aconselha-se a mensuração da altura em algumas parcelas para a o acompanhamento das estimativas.

\section{CONCLUSÃO}

O modelo proposto foi eficiente para estimação da altura de árvores em povoamentos de eucalipto.

A aplicação da metodologia reduz significativamente medições em clones recém- introduzidos no povoamento.

\section{REFERÊNCIAS}

BINOTI, M. L. M. S. Redes neurais artificiais para prognose da produção de povoamentos não desbastados de eucalipto. 2010. 54f. Dissertação (Mestrado em Ciência Florestal) - Universidade Federal de Viçosa, Viçosa, MG, 2010.

BINOTI, D. H. B. et al. Redução dos custos em inventário de povoamentos equiâneos utilizando redes neurais artificiais. Agrária, v. 8, p. 125129, 2012a.

BINOTI, D. H. B. et al. Modelagem da distribuição diamétrica em povoamentos de eucalipto submetidos a desbaste utilizando autômatos celulares. Revista Árvore, v.36, n.5, p.931-939, 2012 b.

BRAGA, A. P.; CARVALHO, A. P. L. F.; LUDERMIR, T. B. Redes neurais artificiais: teoria e aplicações. 2.ed. Rio de Janeiro: LTC, 2007.

COLBERT, K. C.; LARSEN, D. R.; LOOTENS, J. R. Height-diameter equations for thirteen midwestern bottomland hardwood species. Northern Journal of Applied Forestry, v.19, n.4, p.171-176, 2002.
CURTIS, R. O. Height-diameter and height-diameterage equations for second growth Douglas-fir. Forest Science, v.13, p.365-375, 1967.

DIAMANTOPOULOU, M. J. Artificial neural networks as an alternative tool in pine bark volume estimation. Computers and Electronics in Agriculture, v.10, n.3, p.235-244, 2005.

FANG, Z.; BAILEY, R. L. Height-diameter models for tropical forests on Hainan Island in southern China. Forest Ecology and Management, v.110, p.315-327, 1998.

HAYKIN, S. Redes neurais: princípios e prática. Porto Alegre: 2001. 900p.

LEITE, H.G.; ANDRADE, V. C. L. Uso do método da altura relativa em inventário florestal de um povoamento de Pinus. Revista Árvore, v.28, n.6, p.865-873, 2004.

LEITE, H. G. et al. Estimation of inside-bark diameter and heartwood diameter for Tectona grandis Linn. trees using artificial neural networks. European Journal of Forest Research, v.130, n.2, p.263-269, 2011.

MEHTÄTALO, L.; MALTAMO, M.; KANGAS, A. The use of quantile trees in the prediction of the diameter distribution of a stand. Silva Fennica, v. 40, n. 3, p. 501-516, 2006.

STATSOFT, INC. Statistica (Data Analysis Software System), Version 7, 2007.

SILVA, M. L. M. et al. Ajuste do modelo de Schumacher e Hall e aplicação de redes neurais artificiais para estimar volume de árvores de eucalipto. Revista Árvore, v.33, n.6, p.1133-1139, 2009.

ZHANG, S.; BURKHART, H. E.; AMATEIS, R. L. The influence of thinning on tree height and diameter relationships in loblolly pine plantations. Southern Journal of Applied Forestry, v.21, n.4, p.199-205, 1997. 
